\title{
Pengembangan SDM Dalam Arsitektur Bisnis Sebagai Strategi Dalam Optimasi Produktivitas Kinerja SDM
}

\author{
Tanni Maisari ${ }^{[1]^{*}}$, Asti Amalia Nur Fajrillah ${ }^{[2]}$ \\ Jurusan Sistem Informasi, Fakultas Rekayasa Industri ${ }^{[1], ~[2] ~}$ \\ Universitas Telkom \\ Bandung, Indonesia \\ tannimaisari9@gmail.com ${ }^{[1],}$ astiamalia@telkomuniversity.ac.id ${ }^{[2]}$
}

\begin{abstract}
As time goes by the needs and aspects of competence and productivity of Human Resources (HR) are increasingly diverse to form complex communication patterns. To balance and fulfill those needs and aspects, there needs to be an increase in performance, one of them is with enterprise architecture (EA). This study raises the case of one manufacturing company with a focus on the HR management function which has problems regarding the composition and competency of $H R$ that is uneven so that HR productivity is low. One solution to this problem is by designing an EA. The solution produced in this research is expected to be able to meet the company's business requirements which will then be able to help meet the goals of the HR management function and also the company by considering aspects of HR. The design method of this research EA uses TOGAF ADM (The Open Group Architecture Framework) which is one of the frameworks for designing $E A$ by connecting business architecture, data, applications, and technology. TOGAF ADM is flexible so it is possible to proceed with a different framework. In this research, $E A$ design focuses on only three stages, namely the preliminary phase, architecture vision, and business architecture. Business architecture is a phase in the TOGAF ADM which acts as the main component capable of sustaining further architecture. The business architecture contains the definition of baseline architecture and targeting which will be used as guidelines for the basis for the development of integrated information systems for the $H R$ Management Function. Business architecture is very instrumental in helping to handle the issues and risks that occur in the company, so it can facilitate the company to make the right decision.
\end{abstract}

Keywords - Business Architecture, Enterprise Architecture, TOGAF, HR Management.

Abstrak-Seiring berjalannya waktu kebutuhan serta aspek terhadap kompetensi dan produktivitas Sumber Daya Manusia (SDM) semakin beragam sehingga membentuk pola komunikasi yang kompleks. Untuk menyeimbangkan dan memenuhi kebutuhan serta aspek tersebut dibutuhkan adanya peningkatan performa, salah satunya dengan enterprise architecture (EA). Penelitian ini mengangkat kasus salah satu perusahaan manufaktur dengan fokus pada fungsi pengelolaan SDM yang memiliki permasalahan mengenai komposisi dan kompetensi SDM yang tidak merata sehingga produktivitas SDM rendah. Salah satu solusi untuk permasalahan tersebut yaitu dengan perancangan EA. Solusi yang dihasilkan dalam penelitian ini diharapkan mampu memenuhi requirement bisnis perusahaan yang kemudian mampu membantu memenuhi goal fungsi pengelolaan SDM dan juga perusahaan dengan mempertimbangkan aspek SDM. Metode perancangan EA penelitian ini menggunakan TOGAF ADM (The Open Group Architecture Framework) yang merupakan salah satu kerangka kerja untuk merancang EA dengan menghubungkan arsitektur bisnis, data, aplikasi, dan teknologi. TOGAF ADM bersifat fleksibel sehingga sangat memungkinkan untuk dilanjutkan dengan framework yang berbeda. Pada penelitian kali ini perancangan EA berfokus di tiga tahap saja yaitu preliminary phase, architecture vision, dan business architecture. Arsitektur bisnis merupakan fase dalam TOGAF ADM yang berperan sebagai komponen utama yang mampu menopang arsitektur selanjutnya. Arsitektur bisnis berisi pendefinisian arsitektur baseline dan targeting yang nantinya dijadikan pedoman bagi dasar pengembangan sistem informasi yang terintegrasi untuk Fungsi Pengelolaan SDM. Arsitektur bisnis sangat berperan dalam membantu menangani isu dan resiko yang terjadi di perusahaan, sehingga dapat mempermudah perusahaan untuk mengambil keputusan yang tepat.

Kata Kunci-Arsitektur Bisnis, Enterprise Architecture, TOGAF, Pengelolaan SDM.

\section{PENDAHULUAN}

Kontinuitas bisnis suatu perusahaan dilihat berdasarkan sudut pandang bagaimana SDM perusahaan dapat secara maksimal dalam melakukan kinerjanya [11]. Untuk mendapatkan hasil kinerja yang maksimal dibutuhkannya bekal skill yang mumpuni untuk dapat menopang kebutuhan perusahaan seiring berkembangnya zaman [11]. Sehingga penting untuk perusahaan memperhatikan proses pengembangan SDM nya agar tetap stabil dan memberikan dampak yang positif bagi perusahaan serta menjadikan SDM menjadi lebih kompeten dan mampu untuk bersaing dalam segala tantangan di dunia kerja [4]. Karena SDM yang berkompeten merupakan aset berharga yang dimiliki perusahaan [10]. 
Pengelolaan SDM merupakan fungsi pendukung yang ada di perusahaan yang bertanggung jawab dalam pengelolaan dan pengembangan SDM. Sebagai suatu contoh perusahaan manufaktur di daerah Bandung yang memiliki taraf industri strategis, menggunakan teknologi canggih dan berskala internasional. Sehingga perusahaan tersebut membutuhkan SDM yang profesional dan berkompeten kelas dunia. SDM merupakan faktor yang sangat menentukan bagi keberhasilan perusahaan. Namun dalam eksekusi nya, terdapat beberapa permasalahan pertama, komposisi SDM yang tidak merata dengan adanya kelebihan kurang lebih 1000 pegawai dikarenakan work load analysis perusahaan kurang valid karena sistem yang digunakan berbeda sehingga sering terjadi kesalahan dalam migrasi data. Kedua, kesenjangan kompetensi SDM dari tingkat pendidikan serta skill yang dimiliki dimana hanya 17\% SDM yang memiliki gelar sarjana karena tidak ada bantuan sistem informasi yang mampu memetakan skill SDM dan kebutuhan perusahaan. Ketiga, rendah nya produktivitas SDM dengan tingkat pengunduran diri sarjana sebesar 7,3\% karena pengelolaan kompensasi tidak berdasarkan kinerja individu.

Solusi yang dibutuhkan untuk menangani kondisi tersebut yaitu salah satunya dengan menerapkan EA. Dalam melakukan perancangan EA dilakukan pendekatan dari sisi bisnis dan teknologi. Pada penelitian ini perancangan EA difokuskan hanya sampai arsitektur bisnis. Dengan arsitektur bisnis menghasilkan proses bisnis yang telah dikaji sesuai dengan kebutuhan perusahaan untuk menyelesaikan permasalahan yang ada. Proses bisnis juga berperan sebagai pondasi arsitektur sistem informasi dan teknologi dalam perancangan EA. Proses bisnis merupakan komponen utama dalam suatu fungsi bisnis di perusahaan [9]. Dalam alur proses bisnis diperlukan keterlibatan penuh dari stakeholder [9]. Pengelolaan proses bisnis dapat meningkatkan kinerja perusahaan secara keseluruhan [9]. Walaupun banyak perusahaan yang sudah menyadari betapa pentingnya proses bisnis namun masih banyak perusahaan yang belum jelas dan benar bagaimana melakukan perubahan tersebut sesuai dengan akar permasalahan yang ada di perusahaan [12]. Hal ini dikarenakan setiap proses bisnis memiliki karakteristik unik masing-masing dan strategi perubahan tersebut sangat tergantung pada lingkungan dan kemampuan perusahaan dalam merubahnya [12].

\section{TINJAUAN PUSTAKA}

The Open Group Architecture Framework (TOGAF ) adalah sebuah kerangka kerja untuk membangun suatu enterprise architecture [1]. TOGAF menyediakan metode dan tools untuk membantu proses penggunaan dan pemeliharaan suatu Enterprise Architecture [3]. TOGAF berbasiskan model proses yang iteratif (berulang) yang didukung oleh best practices dan sekumpulan aset arsitektur existing yang dapat digunakan kembali (re-usable) [5]. TOGAF dapat digunakan secara bebas oleh perusahaan manapun yang ingin membangun enterprise architecture untuk digunakan di dalam perusahaan tersebut [5]. Dengan tujuan untuk membantu perusahaan dalam merancang arsitektur perusahaan, sehingga arsitektur perusahaan yang dibangun lebih terstruktur dan sistematis [3]. TOGAF ADM memiliki beberapa fase yang diwakili dengan membentuk siklus besar sebagai lambang proses iteratif, fase-fase tersebut antara lain: Preliminary Phase, Architecture Vision, Business Arhcitecture, Information System Architecture, Technology Architecture, Opportunities and Solutions, Migration Planning, Implementation Governance, Architecture Change Management, dan Requirement Management [1].

Pada penelitian ini hanya fokus sampai business architecture / arsitektur bisnis. Preliminary phase menggambarkan inisiasi aktivitas-aktivitas dan persiapan perancangan EA, pendefinisian kerangka kerja arsitektur sesuai kebutuhan perusahaan, dan pendefinisian prinsipprinsip bisnis yang ada di perusahaan [14]. Sehingga sebuah perusahaan dapat terus melakukan perubahan untuk mencapai tujuan bisnis. Architecture Vision merupakan fase pertama perancangan EA menggunakan TOGAF yang mendeskripsikan batasan-batasan arsitektur berupa identifikasi kebutuhan manajemen, pendefinisian perusahaan baik berupa goals, objective dan requirement perusahaan dan lainnya yang mendukung tujuan perancangan EA perusahaan [14]. Business Architecture merupakan fase kedua perangangan EA menggunakan TOGAF yang mendeskripsikan arsitektur bisnis existing dan juga usulan targeting yang disesuaikan dengan fase sebelumnya yaitu architecture vision [2]-[13].

Arsitektur bisnis merupakan prasyarat untuk melanjutkan arsitektur sistem informasi dan teknologi [13]. Arsitektur bisnis diperlukan sebagai sarana yang menunjukkan nilai bisnis dari arsitektur selanjutnya dan juga kunci stakeholder untuk merancang aristektur selanjutnya [13]-[15]. Arsitektur bisnis juga menjadi penting dalam membantu menangani isu dan resiko yang terjadi di perusahaan, sehingga dengan memiliki arsitektur bisnis maka akan mempermudah perusahaan untuk mengambil suatu keputusan tepat yang memungkinkan perusahaan bersaing secara lebih efektif [15][16].

Dalam melakukan perancangan arsitektur bisnis penulis membutuhkan perbandingan antar aplikasi yang dikenal mampu menerapkan pengelolaan SDM dengan baik dalam segi proses bisnis nya. Karena perbandingan dapat dijadikan penulis sebagai tolak ukur dalam melakukan perancangan. Adapun aplikasi yang diambil penulis untuk dijadikan bahan perbandingan yaitu SAP HCM, Talenta by Mekari, dan Open HRMS[6]-[7]-[8]-[17]. 
Tabel 1. Perbandingan Proses Bisnis Aplikasi

\begin{tabular}{|c|c|c|}
\hline Nama Aplikasi & Proses Bisnis yang Dimiliki & Deskripsi \\
\hline \multirow{9}{*}{ SAP HCM } & Organizational Management & Pengelolaan struktur organisasi perusahaan \\
\hline & Personnel Administration & Pengelolaan administrasi pegawai \\
\hline & Time Management & Pengelolaan waktu kerja pegawai \\
\hline & Payroll & Pengelolaan penggajian pegawai \\
\hline & Recruiment & Pengelolaan rekruitasi pegawai \\
\hline & Personnel Development & Pengelolaan segala bentuk kegiatan pengembangan pegawai \\
\hline & Training and Event Management & Pengelolaan aktivitas pegawai \\
\hline & Compensation Management & Pengelolaan kompensasi pegawai \\
\hline & Personnel Cost Planning & Pengelolaan rencana cost pegawai \\
\hline \multirow{5}{*}{ Talenta by Mekari } & Payroll Management & Pengelolaan gaji pegawai \\
\hline & Costing Payroll & $\begin{array}{c}\text { Pembayaran gaji pegawai dengan menggunakan satu platform yang terintegrasi } \\
\text { dengan } e \text {-commerce pegawai dan juga multi-banking }\end{array}$ \\
\hline & Time Management & Pengelolaan waktu pegawai selama kerja yang berpengaruh pada penggajian \\
\hline & HR Administration & Pengelolaan data pegawai dari mulai pegawai lolos rekruitasi hingga jenjang karir \\
\hline & Employee Benefit & Pengajuan pinjaman, klaim pegawai terhadap perusahaan \\
\hline \multirow{7}{*}{ Open HRMS } & Attendance and Leave Management & Pengelolaan absensi pegawai yang terintegrasi dengan data penggajian \\
\hline & Custody Management & $\begin{array}{c}\text { Pengelolaan manajemen aset perusahaan setiap pegawai yang diberi aset oleh } \\
\text { perusahaan }\end{array}$ \\
\hline & Employee Appraisal & Penilaian pegawai menggunakan metode top down dan bottom up secara transparasi \\
\hline & Disciplinary Tracking & $\begin{array}{l}\text { Pelacakan kedisiplinan pegawai sebagai salah satu nilai kinerja pegawai terhadap } \\
\text { tanggung jawabnya }\end{array}$ \\
\hline & Employee Resignation & $\begin{array}{c}\text { Pengunduran diri pegawai, dimana pegawai dapat mengisi rincian yang diperlukan } \\
\text { untuk }\end{array}$ \\
\hline & Payroll & $\begin{array}{c}\text { Pengelolaan penggajian menggunakan metode payslip berdasarkan absen, aturan gaji } \\
\text { dan struktur gaji }\end{array}$ \\
\hline & HR Announcement & $\begin{array}{c}\text { Mengelola pengumuman resmi dengan menyediakan fitur menambahkan lampiran } \\
\text { pada setiap pengumuman }\end{array}$ \\
\hline
\end{tabular}

Berdasarkan Tabel 1 diatas yang menjabarkan proses bisnis yang dimiliki oleh SAP HCM, Talenta by Mekari, dan Open HRMS. Dapat disimpulkan bahwa secara umum proses bisnis utama dalam pengelolaan SDM yaitu proses penggajian, rekruitasi dan, pengembangan pegawai [6]-[7]-[8]-[17].

\section{METODE PENELITIAN}

Penelitian ini fokus menggunakan kerangka kerja TOGAF dan menggunakan model konseptual untuk menggambarkan alur penelitian mengenai perancangan EA pada fungsi pengelolaan SDM berdasarkan permasalahan yang telah didefinisikan pada bab sebelumnya. Penelitian ini dimulai dengan melakukan survey perusahaan apakah sesuai dengan topik penelitian yang akan penulis kembangkan, lalu melakukan MoU dengan pihak perusahaan terkait kebutuhan dokumen yang diperlukan untuk perancangan EA ini seperti RJPP (Rencana Jangka Panjang Perusahaan), RKAP (Rencana Keuangan dan Anggaran Perusahaan), IT Service Catalog, Dokumen Proses Bisnis, dan SOP Perusahaan. Setelah mendapatkan data berdasarkan dokumen yang telah diberikan, penulis melakukan studi literatur menggunakan data yang ada, kemudian penulis melakukan wawancara dan observasi terkait validasi data yang telah dibuat mengenai kesesuaiannya. Tahap wawancara dan observasi akan terus dilakukan hingga pihak perusahaan merasa puas dengan perancangan yang dibuat penulis agar benefit solusi perancangan dapat digunakan oleh perusahaan.

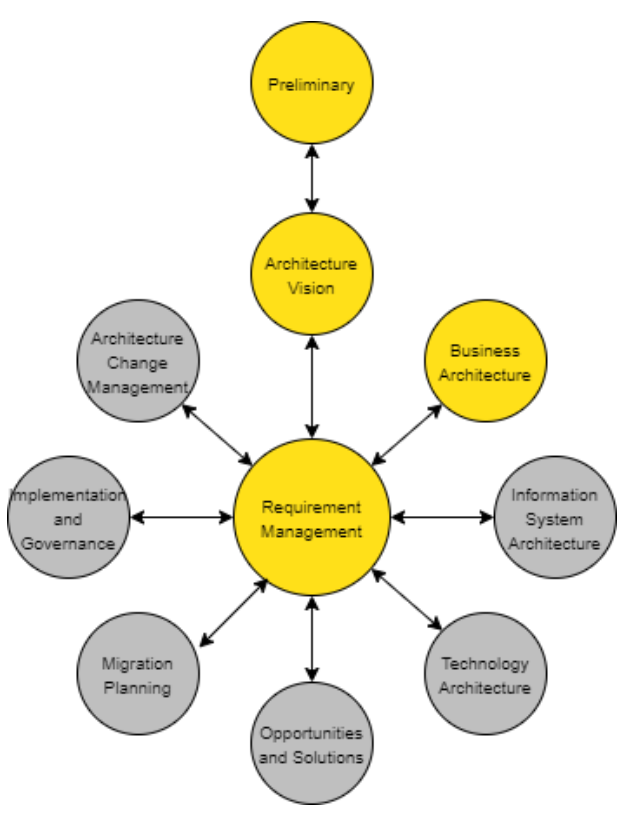

Gambar 1. Fase TOGAF ADM

\section{A. Preliminary Phase}

Preliminary Phase, merupakan tahap persiapan untuk melakukan perancangan EA yang menghasilkan artefak principle catalog [1]-[2]. Principle catalog berisi prinsipprinsip perusahaan yang disesuaikan dengan prinsip framework TOGAF yang nanti nya dijadikan sebagai landasan 
dalam perancangan tiap arsitektur [1]-[2]. Dalam menyusun principle catalog penulis mencari informasi dari dokumen perusahaan yaitu RJPP (Rencana Jangka Panjang Perusahaan) dan RKAP (Rencana Keuangan dan Anggaran Perusahaan) setelah itu penulis juga harus melakukan validasi terhadap pihak perusahaan atas informasi yang didapat dari dokumen, yaitu dengan cara wawancara dengan pihak perusahaan terkait mengenai perancangan EA seperti apa yang mereka inginkan. Lalu penulis melakukan studi literatur berdasarkan informasi yang didapatkan dari perusahaan dengan ilmu perancangan EA sendiri khususnya framework TOGAF sehingga dapat menghasilkan principle catalog yang sesuai dan akurat untuk dijadikan landasan setiap perancangan arsitektur kedepannya.

\section{B. Phase A : Architecture Vision}

Architecture Vision, merupakan tahap pertama perancangan EA menggunakan framework TOGAF [1]-[2]. Fase ini mendeskripsikan batasan-batasan arsitektur, seperti kebutuhan manajemen, pembatasan ruang lingkup, dan identifikasi stakeholder berdasarkan prinsip perusahaan yang sudah di definisikan pada principle catalog di preliminary phase [1]-[2]. Sehingga dihasilkan objective dan requirement yang dijadikan sebagai bekal arsitektur bisnis dan arsitektur sistem informasi. Dalam penyusunan fase ini penulis mendapatkan informasi dari dokumen RJPP, RKAP dan Annual Report perusahaan dengan metode yang sama juga yaitu tetap melakukan wawancara dan studi literatur sebagai bentuk validasi informasi pada perusahaan. perancangan EA menggunakan framewrok TOGAF. Fase ini mendeskripsikan perancangan bisnis dari segi layanan bisnis, proses bisnis dalam pemenuhan requirement yang sudah ditetapkan di fase architecture vision [1]-[2]. Sehingga output dari arsitektur bisnis dapat dijadikan sebagai input utama untuk merancang arsitektur sistem informasi. Dalam penelitian ini menghasilkan business footprint diagram, functional decomposition diagram, business interaction matrix, process flow diagram dan service catalog. Dalam penyusunan fase ini penulis mendapatkan informasi dari dokumen flowchart fungsi dan wawancara dengan fungsi terkait yang nanti dari setiap artefak yang dihasilkan akan disesuaikan dengan fase architecture vision.

\section{HASIL DAN PEMBAHASAN}

Pada bab ini berisi mengenai hasil dan pembahasan penelitian yaitu berupa artefak perancangan EA menggunakan kerangka kerja TOGAF ADM yang berfokus pada tiga fase yaitu preliminary phase, architecture vision, dan business architecture.

\section{A. Preliminary Phase}

Pada fase preliminary ini menetapkan kapabilitas arsitektur yang sesuai melalui prinsip-prinsip arsitektur pada suatu organisasi [5] . Dimana prinsip dibawah ini diambil dari TOGAF Principle dan disesuaikan dengan tujuan fungsi pengelolaan SDM dan perusahaan dalam membangun enterprise architecture [1]-[2].

\section{Phase B : Business Architecture}

Business Architecture, merupakan tahap kedua

Tabel 2. Principle Catalog

\begin{tabular}{|c|c|c|c|c|}
\hline Architecture & Name & Statement & Rationale & Implication \\
\hline \multirow{4}{*}{ Business } & Compliance With Law & $\begin{array}{l}\text { Segala tindak manajemen } \\
\text { fungsi pengelolaan SDM } \\
\text { berada dibawah undang- } \\
\text { undang,kebijakan dan } \\
\text { peraturan yang berlaku }\end{array}$ & $\begin{array}{l}\text { Fungsi pengelolaan SDM } \\
\text { berdiri berdasarkan perusahaan, } \\
\text { undang-undang, kebijakan dan } \\
\text { peraturan Negara sehingga } \\
\text { apapun yang dilakukan fungsi } \\
\text { pengelolaan SDM harus sesuai } \\
\text { dengan kaidah yang berlaku }\end{array}$ & $\begin{array}{c}\text { Fungsi pengelolaan SDM } \\
\text { membantu perusahaan } \\
\text { menjadi perusahaan yang } \\
\text { terpercaya sehingga mudah } \\
\text { melakukan perkembangan } \\
\text { karena tidak adanya } \\
\text { pelanggaran/masalah hukum }\end{array}$ \\
\hline & Primacy of Principles & $\begin{array}{l}\text { Fungsi pengelolaan SDM } \\
\text { menjunjung prinsip } \\
\text { manajemen informasi dalam } \\
\text { melakukan pekerjaan }\end{array}$ & $\begin{array}{c}\text { Satu-satunya cara untuk } \\
\text { memberikan kualitas informasi } \\
\text { yang konsisten dan terukur } \\
\text { dalam membantu pengambilan } \\
\text { keputusan baik di dalam Fungsi } \\
\text { Pengelolaan SDM maupun satu } \\
\text { perusahaan }\end{array}$ & $\begin{array}{l}\text { Meminimalisir kesalahan } \\
\text { pengelolaan informasi baik di } \\
\text { dalam fungsi pengelolaan } \\
\text { SDM maupun satu } \\
\text { perusahaan }\end{array}$ \\
\hline & $\begin{array}{c}\text { Maximize Benefit to The } \\
\text { Enterprise }\end{array}$ & $\begin{array}{c}\text { Memaksimalkan keuntungan } \\
\text { dan manfaat untuk } \\
\text { perusahaan berdasarkan } \\
\text { keputusan manajemen } \\
\text { informasi yang ada di fungsi } \\
\text { pengelolaan SDM }\end{array}$ & $\begin{array}{l}\text { Prinsip ini mampu mewujudkan } \\
\text { "service aboce self" dimana } \\
\text { keputusan yang dibuat } \\
\text { berdasarkan perspektif } \\
\text { keseluruhan akan memiliki } \\
\text { nilai jangka panjang yang lebih } \\
\text { besar daripada keputusan yang } \\
\text { dibuat dari perspektif tertentu. }\end{array}$ & $\begin{array}{l}\text { Sebagai contoh, fungsi } \\
\text { pengelolaan SDM memiliki } \\
\text { prioritas pengembangan } \\
\text { aplikasi yang utama untuk } \\
\text { menunjang kegiatan } \\
\text { bisnisnya. Tentu ini } \\
\text { merupakan keputusan } \\
\text { berdasarkan perspektif } \\
\text { keseluruhan untuk } \\
\text { memaksimalkan keuntungan } \\
\text { perusahaan } \\
\end{array}$ \\
\hline & $\begin{array}{l}\text { Information Management } \\
\text { is Everybody's business }\end{array}$ & $\begin{array}{l}\text { Seluruh entitas fungsi } \\
\text { pengelolaan SDM } \\
\text { berpartisipasi dalam }\end{array}$ & $\begin{array}{c}\text { Seluruh entitias fungsi } \\
\text { pengelolaan SDM perlu } \\
\text { menerapkan teknologi untuk }\end{array}$ & $\begin{array}{l}\text { Dalam melakukan kegiatan } \\
\text { operasional bisnis, seluruh } \\
\text { entitas fungsi pengelolaan }\end{array}$ \\
\hline
\end{tabular}




\begin{tabular}{|c|c|c|c|c|}
\hline Architecture & Name & Statement & Rationale & Implication \\
\hline & & $\begin{array}{c}\text { keputusan manajemen } \\
\text { informasi yang diperlukan } \\
\text { untuk mencapai tujuan bisnis } \\
\text { fungsi maupun perusahaan }\end{array}$ & $\begin{array}{l}\text { memenuhi kebutuhan bisnis. } \\
\text { Untuk memastikan manajemen } \\
\text { informasi selaras dengan bisnis, } \\
\text { seluruh entitas fungsi } \\
\text { pengelolaan SDM harus terlibat } \\
\text { dalam semua aspek lingkungan } \\
\text { informasi }\end{array}$ & $\begin{array}{c}\text { SDM perlu menerima } \\
\text { tanggung jawab untuk } \\
\text { mengembangkan informasi. } \\
\text { Karena informasi merupakan } \\
\text { aspek utama dalam } \\
\text { melakukan kegiatan bisnis }\end{array}$ \\
\hline & Business Continuity & $\begin{array}{c}\text { Dalam melakukan kegiatan } \\
\text { operasional segala aspek } \\
\text { pendukung harus dikelola } \\
\text { dan dipantau meskipun ada } \\
\text { gangguan sistem }\end{array}$ & $\begin{array}{l}\text { Kegiatan bisnis fungsi } \\
\text { pengelolaan SDM harus } \\
\text { mampu beroperasi dalam } \\
\text { mekanisme apapun termasuk } \\
\text { opsi alternatifnya }\end{array}$ & $\begin{array}{c}\text { Adanya pemulihan dan } \\
\text { pemeliharaan sistem } \\
\text { pendukung kegiatan } \\
\text { operasional bisnis secara } \\
\text { berkala dan memiliki opsi } \\
\text { altrnatif untuk mengatasi } \\
\text { berbagai resiko sehingga } \\
\text { kegiatan operasional bisnis } \\
\text { tetap berjalan }\end{array}$ \\
\hline
\end{tabular}

\section{B. Architecture Vision}

Fase architecture vision mendefinisikan ruang lingkup arsitektur, stakeholder, requirement bisnis Fungsi Pengelolaan SDM . Yang nanti nya digunakan sebagai acuan perancangan arsitektur bisnis, salah satu nya yaitu requirement bisnis yang diidentifikasi berdasarkan tujuan, visi dan misi perusahaan terhadap Fungsi Pengelolaan SDM [1]-[2]-[5]. Berikut merupakan Tabel 2 yang berisi pemetaan objective, requirement dan solusi/proses bisnis terkait.

Tabel 3. Requirement Catalog

\begin{tabular}{|c|c|c|}
\hline Objective & Requirement & Solusi/Proses Bisnis Terkait \\
\hline $\begin{array}{l}\text { Meningkatkan kompetensi SDM dengan } \\
\text { tercapainya minimal } 5 \text { program sertifikasi/diklat } \\
\text { sesuai kebutuhan setiap tahun }\end{array}$ & $\begin{array}{l}\text { Adanya program yang mendukung peningkatan } \\
\text { kompetensi pegawai (kerja sama strategis dengan } \\
\text { universitas da perusahaan, beasiswa, coaching, } \\
\text { mentoring) }\end{array}$ & $\begin{array}{l}\text { Proses Perencanaan Kebutuhan Pelatihan, } \\
\text { Proses Pelatihan Pegawai }\end{array}$ \\
\hline \multirow{2}{*}{$\begin{array}{c}\text { Menyelaraskan antara realisasi dan rencana } \\
\text { pegawai mendapatkan sertifikasi/diklat terwujud } \\
100 \%\end{array}$} & $\begin{array}{l}\text { Adanya aplikasi yang mampu membantu memetakan } \\
\text { kebutuhan peningkatan kompetensi pegawai agar tepat } \\
\text { sasaran }\end{array}$ & Proses Perencanaan Kebutuhan Pegawai \\
\hline & $\begin{array}{l}\text { Mengembangkan proses } \\
\text { pegawai yang terstuktur dan terkelola dengan baik }\end{array}$ & Proses Pelatihan Pegawai \\
\hline $\begin{array}{c}\text { Terpenuhinya jumlah pegawai baru yang selaras } \\
\text { dengan kebutuhan setidaknya } 90 \%\end{array}$ & $\begin{array}{l}\text { Mengembangkan aplikasi rekrutmen agar lebih } \\
\text { transparansi kepada pelamar dengan cara menampilkan } \\
\text { seluruh proses dan hasilnya melalui aplikasi tersebut } \\
\text { hingga tahap rekrutmen selesai }\end{array}$ & Proses Rekrutmen Pegawai \\
\hline \multirow{2}{*}{$\begin{array}{l}\text { Menilai ulang dan memproyeksikan WLA } \\
\text { berdasarkan beban kerja di masa depan }\end{array}$} & $\begin{array}{l}\text { Memproyeksikan WLA berdasarkan beban kerja masa } \\
\text { depan pegawai }\end{array}$ & \multirow{2}{*}{ Proses Permintaan Pegawai } \\
\hline & $\begin{array}{l}\text { Adanya aplikasi yang mampu menghitung } \\
\text { sehingga hasilnya akurat }\end{array}$ & \\
\hline \multirow{2}{*}{$\begin{array}{l}\text { Meningkatkan sistem remunerasi perusahaan } \\
\text { berdasarkan kinerja pegawai }\end{array}$} & $\begin{array}{l}\text { Adanya perbaikan struktur sistem remunerasi dan } \\
\text { kompensasi pegawai }\end{array}$ & \multirow{2}{*}{ Proses Pengelolaan Kompensasi dan Benefit } \\
\hline & $\begin{array}{l}\text { Adanya pengkajian pada sistem payroll mengenai } \\
\text { integrasi data dengan sistem penilaian kinerja pegawai }\end{array}$ & \\
\hline
\end{tabular}

\section{Business Architecture}

Fase ini berisi deskripsi arsitektur bisnis existing dan targeting (sebagai usulan). Dimana targeting dibuat berdasarkan objektif organisasi yang memuat proses bisnis, fungsi organisasi, layanan dan strategi yang digunakan untuk mendukung fase sebelumnya yaitu Architecture Vision, yang diharapkan mampu menjadi usulan yang efektif dan efisien sehingga dapat digunakan perusahaan[1]-[2]-[5]. Berikut beberapa artefak yang dihasilkan dari fase business architecture ini :

\section{1) Business Footprint Diagram}

Menggambarkan hubungan antara driver, goal, objective, dan capability [2]. Diagram ini membantu perusahaan untuk melihat alur tujuan yang harus dicapai yaitu dengan memenuhi requirement yang telah dipetakan berdasarkan goal dan objective fungsi pengelolaan SDM dan juga perusahaan, agar solusi yang akan diputuskan tepat sesuai requirement [2]. 


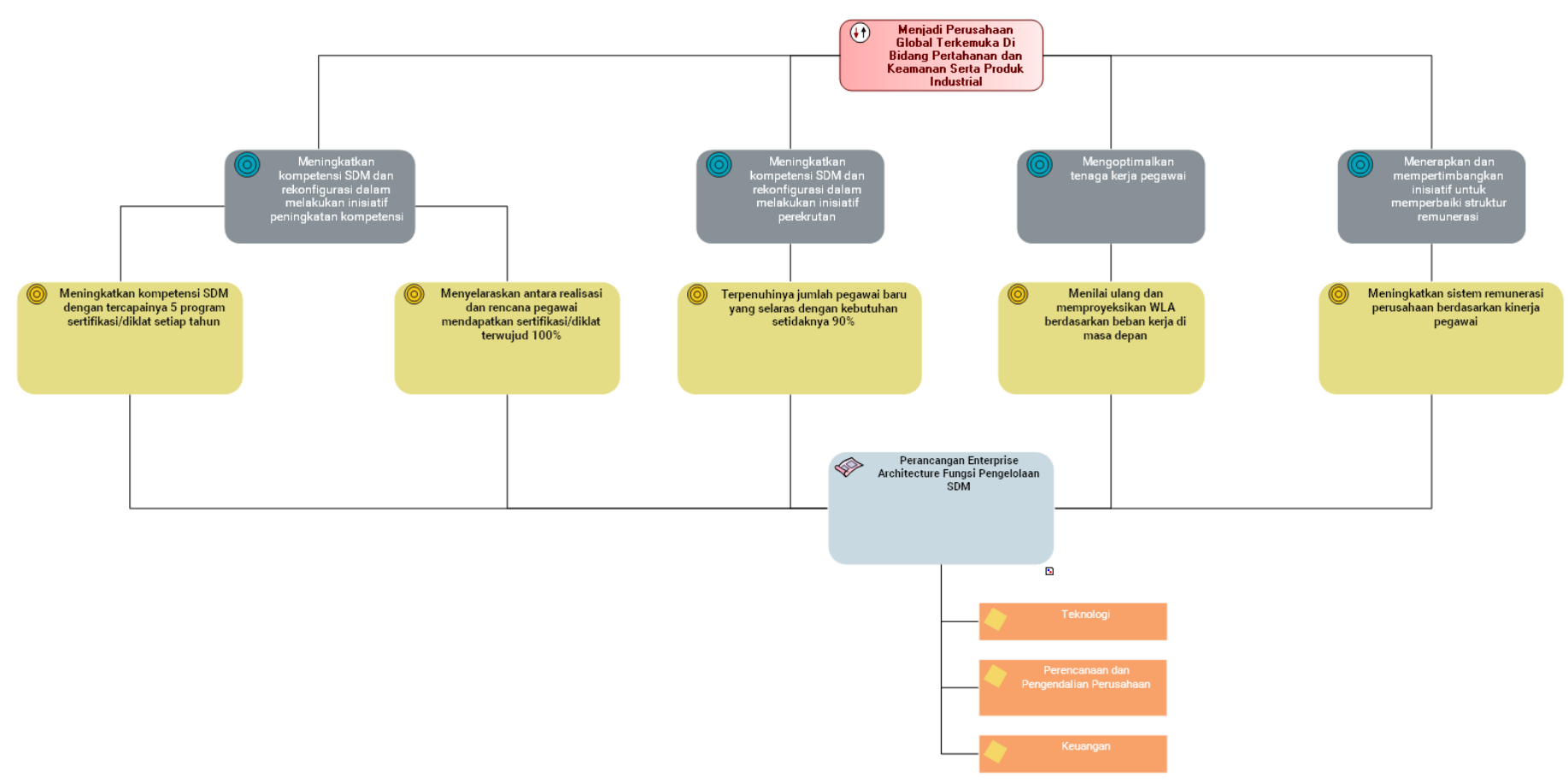

Gambar 2. Business Footprint Diagram

Pada gambar $\mathrm{x}$ merupakan artefak business footprint diagram, dimana yang berwarna pink merupakan driver perusahaan, abu-abu merupakan goal fungsi pengelolaan SDM yang telah diturunkan dari goal perusahaan. Lalu kuning merupakan objective fungsi pengelolaan SDM yang merupakan acuan yang dijadikan sebagai pengukur pencapaian optimal atas goal fungsi pengelolaan SDM. Biru muda merupakan solusi yang akan dilakukan untuk memenuhi objective, goal fungsi pengelolaan SDM dan juga driver perusahaan yaitu perancangan enterprise architecture fungsi pengelolaan SDM Jingga merupakan capability fungsi pengelolaan SDM yaitu fungsi teknologi, perencanaan dan pengendalian perusahaan, keuangan.
2) Business Interaction Matrix

Menjelaskan interaksi antar proses bisnis pada Fungsi Pengelolaan SDM [2]. Providing berarti proses bisnis yang menyediakan output yang nantinya dijadikan input oleh proses bisnis lain yang membutuhkan. Sedangkan consuming berarti proses bisnis yang menggunakan output dari providing. Interaksi proses bisnis dibutuhkan untuk mengetahui alur pertukaran informasi dalam proses bisnis tersebut.

Tabel 4. Business Interaction Matrix

\begin{tabular}{|c|c|c|c|c|c|}
\hline Providing/Consuming & Permintaan Pegawai & Rekrutmen Pegawai & $\begin{array}{c}\text { Perencanaan } \\
\text { Kebutuhan Pelatihan }\end{array}$ & $\begin{array}{l}\text { Pelaksanaan } \\
\text { Pelatihan }\end{array}$ & $\begin{array}{c}\text { Pengelolaan } \\
\text { Kompensasi \& } \\
\text { Benefit }\end{array}$ \\
\hline Permintaan Pegawai & N/A & N/A & N/A & N/A & N/A \\
\hline $\begin{array}{c}\text { Perencanaan Kebutuhan } \\
\text { Pelatihan } \\
\end{array}$ & $\begin{array}{c}\text { Metode Pengadaan } \\
\text { Pegawai } \\
\end{array}$ & Data Pegawai Baru & N/A & N/A & N/A \\
\hline Pelaksanaan Pelatihan & $\begin{array}{l}\text { Metode Pengadaan } \\
\text { Pegawai }\end{array}$ & Data Pegawai Baru & $\begin{array}{c}\text { Metode dan Jenis } \\
\text { Diklat, Kalender } \\
\text { Diklat }\end{array}$ & N/A & N/A \\
\hline
\end{tabular}

\section{3) Functional Decomposition Diagram}

Menggambarkan fungsi dengan proses bisnis yang digunakan untuk pemenuhan goal perusahaan [2]. Dari beberapa proses bisnis yang ada pada fungsi pengelolaan
SDM diambil enam proses bisnis, dimana enam proses bisnis tersebut yaitu proses yang sesuai dengan requirement bisnis yang telah didefinisikan pada requirement catalog dan footprint diagram. 


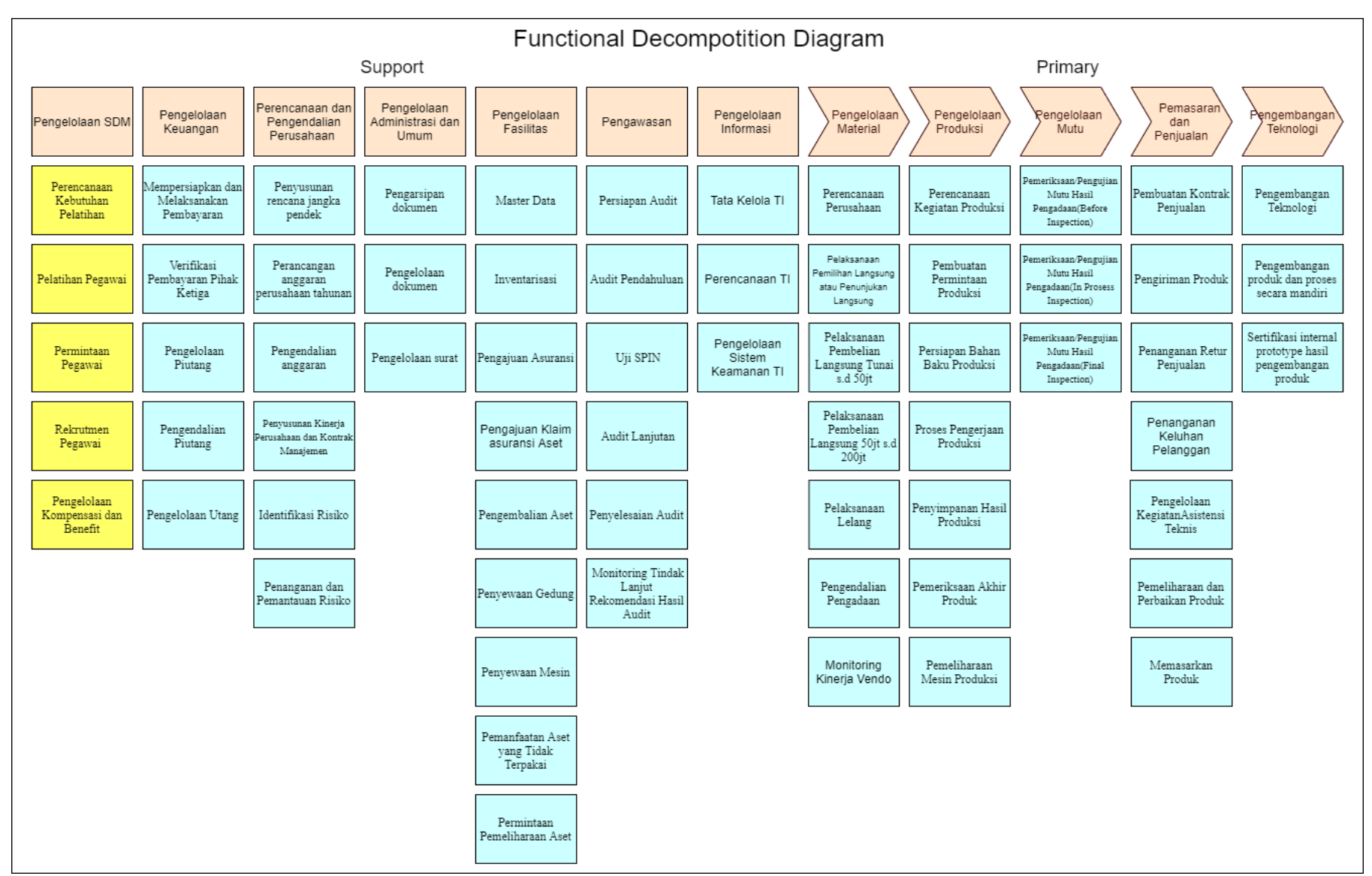

Gambar 3. Functional Decomposition Diagram

\section{4) Process Flow Diagram}

Menggambarkan alur proses bisnis pada Fungsi Pengelolaan SDM [2]. Dimana penggambaran diagram dijelaskan Tabel 4 yang memuat deskripsi proses bisnis, aktor yang terkait dalam proses bisnis tersebut, business rules yaitu komponen proses yang wajib dilakukan dalam suatu proses bisnis tersebut, permasalahan yang ada pada proses bisnis tersebut yang akan diselesaikan, dan solusi yang merupakan langkah penyelesaian dari masalah yang timbul dalam proses bisnis tersebut. Process flow ini membantu melihat permasalahan yang terjadi secara detail sehingga solusi yang diberikan pun detail karena diambil berdasarkan permasalahan proses bisnis tersebut.

Tabel 5. Process Flow

\begin{tabular}{|c|c|c|}
\hline Proses Bisnis Utama & $\begin{array}{c}\text { Proses Bisnis Overview / } \\
\text { Organizational Process }\end{array}$ & Deskripsi Proses Bisnis \\
\hline \multirow{5}{*}{$\begin{array}{c}\text { Proses Rekrutmen \& } \\
\text { Seleksi }\end{array}$} & \multirow{5}{*}{$\begin{array}{c}\text { Proses Permintaan } \\
\text { Pegawai }\end{array}$} & $\begin{array}{l}\text { Deskripsi : Proses permintaan pegawai dimulai ketika divisi terkait membutuhkan pegawai melalui } \\
\text { pengisian pengadaan pegawai yang nantinya akan divalidasi oleh Bagian Analisis Jabatan, setelah } \\
\text { itu dilakukan analisis WLA apakah divisi terkait benar-benar layak membutuhkan pegawai baru } \\
\text { atau tidak. Apabila dari hasil WLA benar membutuhkan maka Bagian Perencanaan Tenaga Kerja } \\
\text { akan menetapkan keputusan kebutuhan pegawai dan melakukan koordinasi dengan Divisi } \\
\text { Perencanaan Perusahaan untuk menetapkan anggaran di RKAP (Rencana Kerja dan Anggaran } \\
\text { Perusahaan) apakah akan diadakan rekrutmen atau rotasi pegawai untuk memenuhi kebutuhan } \\
\text { pegawai di divisi terkait. Jika hasil WLA sebaliknya maka proses akan selesai dan tidak } \\
\text { dilanjutkan. }\end{array}$ \\
\hline & & $\begin{array}{l}\text { Aktor : Divisi Terkait, Staff dan Manajer Perencanaan Tenaga Kerja, Staff dan Manajer Analisis } \\
\text { Jabatan, Manajer Dept. Talenta dan Divisi Perencanaan Perusahaan }\end{array}$ \\
\hline & & $\begin{array}{l}\text { Business Rules : Proses validasi form harus dilakukan sebelum melakukan analisis WLA, } \\
\text { Keputusan untuk melakukan pengadaan pegawai dilakukan berdasarkan form yang sudah valid } \\
\text { dan hasil analisis WLA. }\end{array}$ \\
\hline & & $\begin{array}{l}\text { Permasalahan : Perhitungan WLA berdasarkan kinerja saat ini dan menggunakan microsoft excel } \\
\text { sehingga sering terjadi perbedaan data ketika sedang migrasi data dari excel ke sistem sehingga } \\
\text { hasil menjadi tidak akurat }\end{array}$ \\
\hline & & $\begin{array}{l}\text { Solusi : Perbaikan struktur perhitungan WLA berdasarkan kinerja masa depan dengan proses yang } \\
\text { sistematis }\end{array}$ \\
\hline
\end{tabular}


Jurnal SISFOKOM (Sistem Informasi dan Komputer), Volume 09, Nomor 01, PP 122 - 131

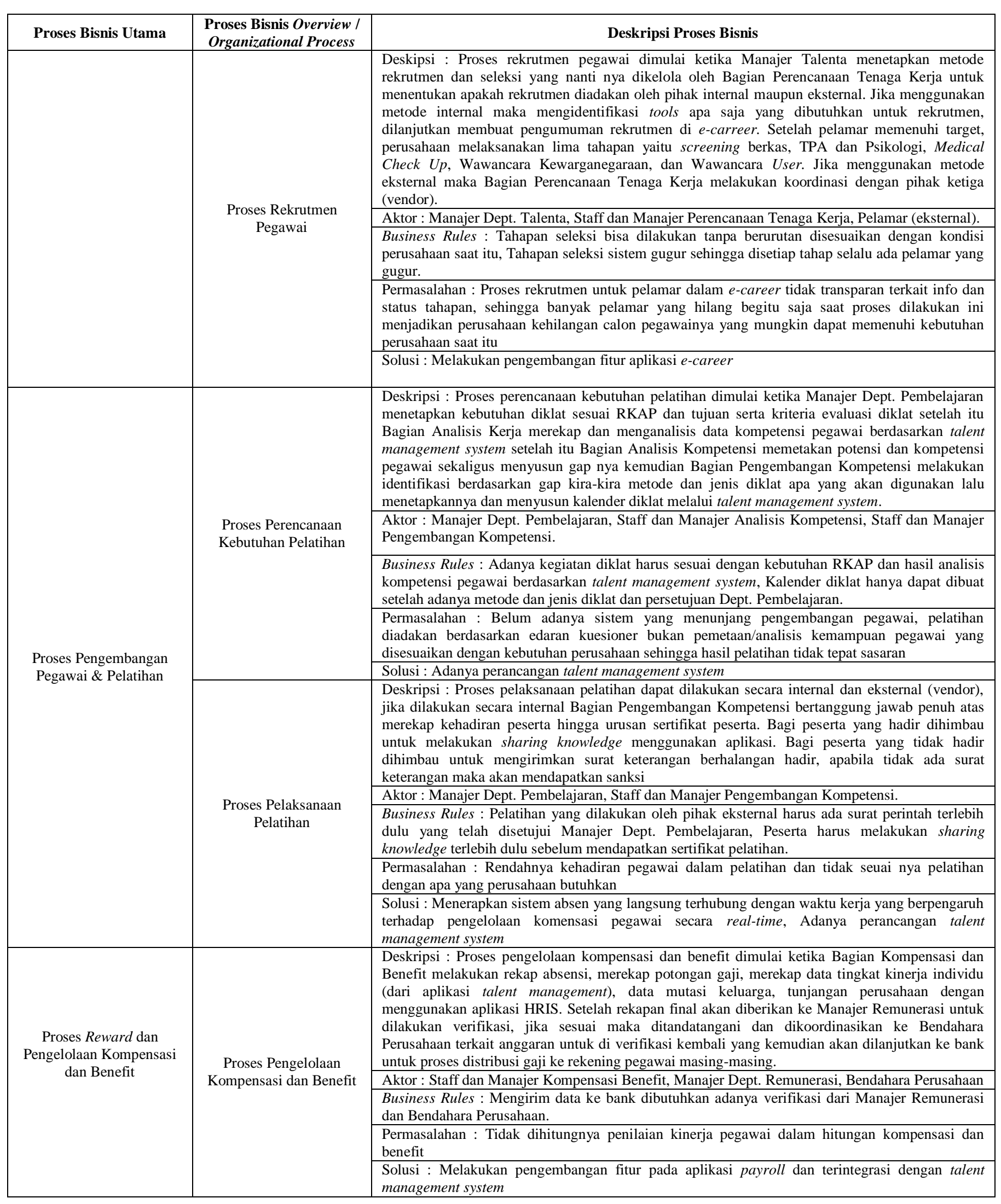


5) Service Catalog

Memetakan layanan yang ada pada fungsi Pengelolaan SDM, layanan ini didapat berdasarkan proses bisnis yang ada di artefak process flow. Dimana layanan ini dapat dijadikan sebagai acuan pengembangan arsitektur sistem informasi untuk menyempurnakan solusi yang diberikan pada arsitektur bisnis.

Tabel 6. Service Catalog

\begin{tabular}{|l|l|}
\hline \multirow{2}{*}{ Service } & Proses Bisnis \\
\hline \multirow{2}{*}{$\begin{array}{l}\text { Pelatihan dan } \\
\text { Pengembangan SDM }\end{array}$} & Proses Perencanaan Kebutuhan Pelatihan \\
\cline { 2 - 2 } & Proses Pelatihan Pegawai \\
\hline \multirow{3}{*}{ Pengelolaan Karir SDM } & Proses Permintaan Pegawai \\
\cline { 2 - 2 } & Proses Rekrutmen Pegawai \\
\cline { 2 - 2 } & Proses Rotasi Pegawai \\
\hline Pengelolaan Remunerasi & Proses Pengelolaa Kompensasi dan Benefit \\
\hline
\end{tabular}

\section{KESIMPULAN}

Perancangan enterprise architecture penelitian ini menggunakan TOGAF ADM yang berfokus pada fase preliminary, architecture vision, dan business architecture. Sehingga dapat dikatakan bahwa perancangan ini mutlak belum selesai hingga menjadi blueprint enterpise architecture. Karena output dari penelitian ini hanya berupa blueprint arsitektur bisnis yang merupakan pondasi dalam perancangan EA dan harus dilanjutkan ke fase selanjutnya untuk menghasilkan output perancangan EA yang utuh. Dengan blueprint arsitektur bisnis pada penelitian ini diharapkan dapat membantu menyelesaikan masalah pada Fungsi Pengelolaan SDM dalam segi perancangan bisnis.
Dalam perancangan solusinya, preliminary phase membantu mendefinisikan prinsip yang harus diterapkan dalam fungsi pengelolaan SDM untuk merancang EA. Pada architecture vision membantu mendefinisikan alur solusi yang terstruktur dimulai dari driver perusahaan, goal fungsi SDM, dan requirement sebagai hal yang dilakukan dalam perancangan EA untuk memenuhi driver dan goal tersebut. Lalu pada business architecture merupakan tahap eksekusi pertama perancangan EA dalam segi pembangunan bisnis yang disesuaikan dengan hasil architecture vision dan preliminary phase.

Berdasarkan analisis artefak yang telah dihasilkan dapat dilihat bahwa betapa krusial dan pentingnya proses pengembangan SDM dalam perusahaan di penilitian ini, dilihat dari requirement awal yang diturunkan berdasarkan goal dan objective fungsi pengelolaan SDM. Dimana requirement tersebut memuat beberapa hal yang akan dipenuhi dalam perancangan EA ini untuk membantu tercapainya goal fungsi pengelolaan SDM yang merupakan turunan dari goal perusahaan.

Permasalahan yang ada pada penelitian ini berupa komposisi, kompetensi dan produktivitas SDM yang tidak sesuai yang dapat dilihat pada Tabel 7 Sehingga dapat disimpulkan proses pengembangan SDM merupakan hal yang sangat krusial dikalangan pengelolaan SDM perusahaan. Dengan memperbaiki proses pengembangan SDM pada penelitian ini dapat menjadi kunci utama untuk mencapai goal fungsi pengelolaan SDM dan juga perusahaan.

Tabel 7. Pemetaan Kesimpulan

\begin{tabular}{|c|c|c|c|}
\hline Permasalahan & Akar Permasalahan & Solusi & Sumber \\
\hline Komposisi SDM tidak merata & $\begin{array}{l}\text { Perhitungan WLA berdasarkan beban kerja } \\
\text { saat ini dan tidak akurat, sulitnya mencari } \\
\text { SDM yang sesuai kebutuhan perusahaan }\end{array}$ & $\begin{array}{l}\text { Perbaikan struktur perhitungan WLA } \\
\text { berdasarkan kinerja masa depan dengan } \\
\text { proses yang sistematis } \\
\text { melakukan pengembangan e-career }\end{array}$ & \multirow{3}{*}{$\begin{array}{l}\text { Analisis artefak: } \\
\text { requirement catalog, } \\
\text { business footprint } \\
\text { diagram, business } \\
\text { interaction matrix, } \\
\text { functional decomposition } \\
\text { diagram, process flow } \\
\text { diagram, dan service } \\
\text { catalog }\end{array}$} \\
\hline Kompetensi SDM tidak merata & $\begin{array}{l}\text { Adanya kesenjangan tingkat pendidikan, } \\
\text { perencanaan dan pelaksanaan pelatihan } \\
\text { berdasarkan edaran kuesioner sehingga hasil } \\
\text { pelatihan tidak tepat sasaran }\end{array}$ & $\begin{array}{l}\text { Mengembangkan talent management } \\
\text { system khususnya mengenai } \\
\text { organizational development }\end{array}$ & \\
\hline Produktivitas SDM rendah & $\begin{array}{l}\text { Tidak dihitungnya hasil penilaian kinerja SDM } \\
\text { selama bekerja sehingga SDM merasa kurang } \\
\text { diapresiasi, sulit melakukan migrasi data hasil } \\
\text { penilaian kinerja SDM }\end{array}$ & $\begin{array}{l}\text { Memperbaiki struktur kompenasi dengan } \\
\text { mencantumkan penilaian kinerja SDM }\end{array}$ & \\
\hline
\end{tabular}

Berdasarkan tabel tersebut diketahui bahwa dengan memperbaiki proses pengembangan SDM terlebih dulu maka dapat mengatasi permasalahan yang lain. Apabila proses pengembangan SDM sudah teratasi dengan mengembangkan talent management system maka lebih mudah bagi perusahaan mendapatkan hasil penilaian kinerja SDM dan tentunya perhitungan WLA juga menjadi akurat. Untuk membangun talent management system yang sesuai dengan requirement bisnis harus dilanjutkan di fase arsitektur sistem informasi.

\section{DAFTAR PUSTAKA}

[1] The Open Group Architecture Framework. (2020). Introduction to the ADM. https://pubs.opengroup.org/architecture/togaf8-doc/arch/chap03.html

[2] The Open Group Architecture Framework. (2020). The TOGAF Standard, Version 9.2 - Architectural Artifacts. Pubs.Opengroup.Org. https://pubs.opengroup.org/architecture/togaf9-doc/arch/chap31.html

[3] Suryadi, S., \& Fernandes Andry, J. (2017). Perancangan Enterprise Architecture Mengunakan Togaf Architecture Development Method (Studi Kasus: Yakuza Gym Jakarta Barat). 2(2502), 129-134. https://journal.uhamka.ac.id/index.php/teknoka/article/view/748 
[4] Johan Oscar Ong, M. M. (2020). Strategi Pengelolaan Sdm Dalam Peningkatan Kinerja Perusahaan Berkelanjutan Di Era Industri 4.0. 2. JURNAL BECOSS (Business Economic, Communication, and Social Sciences), Vol.2 No.1 January 2020: 159-168

[5] Murti, D. N., Prasetyo, Y. A., \& Fajrillah, A. A. N. (2017). Perancangan Enterprise Architecture Pada Fungsi Sumber Daya Manusia (SDM) Di Universitas Telkom Menggunakan Togaf ADM. Jurnal Rekayasa Sistem \& Industri (JRSI), 4(01), 47. https://doi.org/10.25124/jrsi.v4i01.233

[6] Tutorialkart. (2018). SAP HR - Maintain User Parameters in SAP. Tutorialkart. https://www.tutorialkart.com/sap-hr/maintain-userparameters-in-sap/

[7] Talenta. (2020). Talenta - Software Payroll \& Sistem HR indonesia Terbaik. Talenta by Mekari. https://www.talenta.co/

[8] Technologies, C. (2020). Open HRMS _ MOST ADVANCED OPEN SOURCE HR MANAGEMENT SOFTWARE. Cybrosys Limited. https://www.openhrms.com/

[9] Sari, S. K., \& Asniar, A. (2015). Analisis Dan Pemodelan Proses Bisnis Prosedur Pelaksanaan Proyek Akhir Sebagai Alat Bantu Identifikasi Kebutuhan Sistem. JURNAL INFOTEL - Informatika Telekomunikasi Elektronika, 7(2), 143. https://doi.org/10.20895/infotel.v7i2.42

[10] Saelendra, E. (2014). Pengelolaan Dan Pengembangan Sumber Daya Manusia Pada Pt . Istana Motor Indah. Agora, 2(1), 12.

[11] S R, V. L., \& Kennedy, H. (2017). The Role of Business Sustainability in Human Resource Management: A Study on Indian Manufacturing Companies. The South East Asian Journal of Management, 11(1), 7085. https://doi.org/10.21002/seam.v11i1.7739.
[12] Candra, A. L. (2017). Analisis Dan Rekayasa Proses Bisnis Pada Bagian Layanan Akademik Di Sekretariat Fakultas Sains Dan Teknologi Universitas Ma Chung. J@ti Undip : Jurnal Teknik Industri, 12(3), 161.

[13] Lalu, H. (2016). Perancangan Arsitektur Bisnis Pengembangan Pembelajaran Perguruan Tinggi Di Indonesia Berbasis Organizational Learning Dengan Pendekatan Togaf Adm. Jurnal Rekayasa Sistem \& Industri (JRSI), 3(03), 54. https://doi.org/10.25124/jrsi.v3i03.24

[14] Silva, N., \& Mira, M. (2017). 2017 IEEE 21st International Enterprise Distributed Object Computing Conference A Viewpoint for Analyzing Enterprise Architecture Evolution https://doi.org/10.1109/EDOC.2017.13

[15] Roelens, B., \& Poels, G. (2017). The Design of a Modeling Technique to Analyze the Impact of Process Simulation Throughout the Business Architecture. 37-52. https://doi.org/10.1007/978-3-319-68185-6

[16] Wißotzki, M., \& Sandkuhl, K. (2017). The Digital Business Architect Towards Method Support for Digital Innovation and Transformation. 352-362. https://doi.org/10.1007/978-3-319-70241-4

[17] E.Darmaningrat, H.Astuti, \& A.Rizky (2019). Analisis Kesenjangan Dan Pemodelan Proses Bisnis Human Capital Management Pada PTPN XI Berdasarkan Best Practice SAP. Jurnal Teknologi Informasi dan Ilmu Komputer (JTIIK) DOI: 10.25126/jtiik.20196937 Vol. 6, No. 2, April 2019, hlm. 187-194 